\title{
Cibercultura e existência em tempo real Contribuição para a crítica do modus operandi de reprodução cultural da civilização mediática avançada ${ }^{1}$
}

\author{
Eugênio Trivinho \\ PUC-SP \\ eugeniotrivinho@uol.com.br
}

\begin{abstract}
Resumo: O trabalho está dedicado à caracterização e crítica da significação social-histórica da existência em tempo real na cibercultura. Reverberação de interesses estruturais e convenientes - de corporações do ramo comunicacional, Estados e consumidores (ouvintes/telespectadores/usuários) -, a existência em tempo real cumpre importante função na dinâmica social do capitalismo contemporâneo. Dos fatos econômicos aos culturais, do trabalho ao tempo livre, estejam em jogo necessidades de governos, da indústria ou do comércio, tudo passa pela experiência desse processo que doravante radica na reprodução social-histórica e cultural da civilização mediática.

Após reunir evidências empíricas em prol da consolidação do conceito de cibercultura como categoria de época, o texto insere e trata, nesse contexto, a existência em tempo real como experiência antropológica majoritária, mapeando-lhe as estruturas de base e conseqüências sociais, a fim de apreender a sua especificidade tecnocultural.
\end{abstract}

Palavras-chave: Cibercultura. Existência em tempo real. Reprodução social-histórica.

\begin{abstract}
This work is dedicated to the characterization and critique of the sociohistorical significance of existence in real time in cyberculture. A reverberation of structural and convenient interests - of corporations of the communicational field, States and consumers (listeners/telespectators/users)
\end{abstract}

1 Texto apresentado ao Grupo de Trabalho "Comunicação e Cibercultura", no XVI Encontro Nacional da COMPÓS, realizado na Universidade Tuiuti do Paraná (UTP), em Curitiba/PR, em junho de 2007. O artigo resulta do Projeto de Pesquisa em desenvolvimento no PEPGCOS/PUC-SP, com apoio do CNPq.

2 Professor e Vice-Coordenador do PEPGCOS-PUC-SP, pesquisador do CNPq e coordenador do CENCIB - Centro Interdisciplinar de Pesquisas em Comunicação e Cibercultura (PUC-SP). 
-, existence in real time plays an important role in the social dynamics of contemporary capitalism. From economic to cultural factors, from work to leisure time, be it the needs of governments, industry or commerce at stake, everything goes through the experience of this process that is henceforth rooted in the sociohistorical and cultural reproduction of the mediatic civilization.

After garnering empirical evidence substantiating the consolidation of the concept of cyberculture as a category of our times, the text inserts and discusses, in this context, the existence of real time as a major anthropological experience, mapping its base structures and social consequences in order to fathom its technocultural specificity.

Keywords: mediatic civilization, cyberculture, glocal condition, existence in real time, sociohistorical reproduction, theoretical critique.

Résumé: Ce travail est consacré à la caractérisation et la critique au sens social-historique de l'existence en temps réel dans la cyberculture. Echo d'intérêts structuraux et convenables - de corporations de la branche de communication, d'Etats et de consommateurs (auditeurs/téléspectateurs/usagers) -, l'existence en temps réel assure une importante fonction dans la dynamique sociale du capitalisme contemporain. Des faits économiques à ceux culturels, des moments en travail à ceux en temps libre, que soient-ils en jeu les besoins des gouvernements, de l'industrie ou du commerce, tout passe par l'expérience de ce processus qui désormais s'enracine dans la reproduction social-historique et culturelle de la civilisation médiatique.

Après avoir réuni des évidences empiriques en faveur de la consolidation du concept de cyberculture comme catégorie d'époque, le texte insère et traite, dans ce contexte-là, l'existence en temps réel comme une expérience anthropologique majoritaire, et définit ses structures de base et ses conséquences sociales, afin de saisir sa spécificité technoculturelle.

Mots-clé: civilisation médiatique, cyberculture, condition globale, existence en temps réel, reproduction social-historique, critique théorique.

Resumen: El trabajo está dedicado a la caracterización y a la crítica de la significación socio-histórica de la existencia en tiempo real en la cibercultura. En tanto una reverberación de intereses estructurales y convenientes - de corporaciones del ramo comunicacional, Estados y consumidores (oyentes/telespectadores/usuarios) -, la existencia en tiempo real cumple una importante función en la dinámica social del capitalismo contemporáneo. Desde los acontecimientos económicos a los culturales, desde el trabajo al tiempo libre, estando en juego las necesidades de los gobiernos, de la industria o del comercio, todo pasa por la experiencia de ese proceso que, en adelante, radica en la reproducción socio-histórica y cultural de la civilización mediática.

Luego de reunir evidencias empíricas en pro de la consolidación del concepto de cibercultura como categoría de época, en ese contexto el texto inserta y trata la existencia en tiempo real como una experiencia antropológica mayoritaria, delineando el mapa de sus estructuras de base y de sus consecuencias sociales, con el objetivo de aprehender su especificidad tecnocultural.

Palabras clave: civilización mediática, cibercultura, condición glocal, existencia en tiempo real, reproducción socio-histórica, crítica teórica. 


\section{I - NOTA INTRODUTÓRIA}

O fenômeno da existência em tempo real tem sido objeto de pouca atenção crítica por parte da teoria social orientada ao esclarecimento dos processos da comunicação e da civilização mediática avançada. ${ }^{3}$ A relativa abstenção da tarefa seja no Brasil, seja no exterior - de extrair dessa experiência social (e, sobretudo, de suas estruturas tecnológicas e culturais) as devidas conseqüências, com efeito, não causaria estranheza - tantos os acontecimentos e fenômenos historicamente emergentes desacompanhados dos rigores da teoria - não fosse a existência em tempo real processo mediático de capital importância para a compreensão dos pressupostos do modus operandi e dos horizontes dessa civilização. Prescindir de apreender esse fenômeno - num tempo em que ele se encontra banalizado pela absorção das redes digitais no cotidiano -, mais que implicar renúncia à elaboração reflexiva da lógica da vida humana em condições mediáticas avançadas, põe em risco o próprio fundamento do empreendimento teórico sobre o processo civilizatório atual.

O presente artigo visa contribuir para a superação dessa lacuna. Seu foco precípuo é a significação social-histórica desse modo de existência na cibercultura suas estruturas de base e de fundo, sua especificidade antropológica, sua tipificação tecnocultural, suas conseqüências sociais e suas tendências prováveis. O interesse em jogo - fique claro de partida - não recai tanto sobre o que é existir em tempo real abordagem que, por suposto, representaria reduzir demais a questão -, mas sobre o que significa, propriamente, do ponto de vista social-histórico, o fato de existir uma existência mesma em tempo real, como processo comunicacional genérico ou fato social total (cf. MAUSS 1974, p. 39-184) da civilização mediática avançada.

\section{II - CIBERCULTURA COMO CATEGORIA DE ÉPOCA}

Na literatura ensaística internacional, o conceito de cibercultura, embora em formação e sem consenso vigente, granjeou, grosso modo, sentido específico, embora não estrito. Compreende relações e práticas vinculados ao objeto infotecnológico (de base ou móvel), ao cyberspace e/ou a alteridades virtuais (outro mediatizado e/ou

\footnotetext{
3 Em textos anteriormente redigidos, inclusos em obra no prelo (TRIVINHO, 2007), encetaram-se passos definidos nessa direção.
} 
digitalizado), bem como todos os fatores de base necessários - o capital cognitivo conforme e o capital econômico de acesso privado pleno às senhas infotécnicas de acesso (TRIVINHO, 2007, Parte II, Caps. 2, 4) - para a viabilização, desenvolvimento e expansão dessas relações e práticas, por pressuposto calcadas na interatividade como forma predominante de vínculo social, de validação da ação (individual ou coletiva) e de presença do si-próprio (como sujeito típico, o ser interativo) no campo social.

Embora o conceito de cibercultura pressuponha que, desde pelo menos o início dos anos 90 do século passado, tais relações e práticas tenham por referência exponencial o (ou gire em torno do) cyberspace, a presença do caráter online não é nem necessária, nem exclusiva. A cibercultura se joga tanto no universo dos fatos e processos exclusivamente internos ao cyberspace, quanto no dos que vicejam e se esgotam em contexto off-line. Esse aspecto ratifica a acepção sociológica do conceito. Cibercultura diz respeito, também e por óbvio, à cultura informática padrão (na qualidade de capital cognitivo demonstrativo de "aculturação específica”, de dotação de competência e habilidade pragmático-operatórias e simbólicas dentro e fora da rede) das classes sociodromocráticas da época (TRIVINHO, 1999, Parte I, Cap. V), grupos sociais dotados de algum tipo de acesso - do mais limitado e coletivo ao mais individualizado e pleno - às senhas infotécnicas de acesso e que as utilizam regularmente, na esfera do trabalho, na do domo e/ou em lugar alternativo (público ou privativo). Em particular, cibercultura diz igualmente respeito ao background cognitivo típico dos movimentos ou redes sociais informatizados e ciberespacializados, isto é, que se definem pela prática microinformática como forma hodierna de ação social e política. Nesse recorte, cibercultura equivale a um capital social de sobrevivência cultural na fase globalitária do capitalismo.

Dadas tais matizações de sentido, o conceito de cibercultura abrange, per se, largo cinturão de elementos e processos empíricos - do objeto ao sujeito e deste ao entorno - que acabou por se tornar o próprio contexto concreto (material, simbólico e imaginário, imediato e mediato) da vida humana na civilização mediática avançada (TRIVINHO, 1999, 2001, p. 59-62, 2007). A cibercultura corresponde à formação societária e tecnocultural articulada e modulada pelo conjunto de necessidades sociais compulsórias historicamente consolidadas em torno da reciclagem estrutural 
e da apropriação contínuas das senhas infotécnicas de acesso. Em outras palavras, abarca tanto o arranjamento material, simbólico e imaginário contemporâneo, quanto os processos sociais internos (estruturais e conjunturais) que lhe dão sustentação.

Bom número de signos e tendências existentes ou emergentes na vida cultural em geral valida e fundamenta - e, não raro, contribui para levar adiante (o que constitui, de fato, tarefa do presente artigo) - o estiramento do diâmetro simbólico do conceito de cibercultura, algo que, como definição, encerra, de certa forma, para além da presunção ou da hipótese, valor de constatação. A seguir, arrolam-se emblemas e aspectos notórios para sustentação desse argumento.

[1] No início do século XX, o modelo radiofônico e cinematográfico de comunicação reconfigurou o jornalismo impresso, que então teve de se acomodar às condições incipientes da indústria do tempo real e da reprodução técnica da imagem. $\mathrm{Na}$ década de 50, a estética televisiva, com o seu frenesi típico, malgrado a sua superficialidade conteudística, capitaneou todos os media, e assim prosseguiu por quase trinta anos. Em meados dos anos 90, consumou-se novo rearranjo de dados. $\mathrm{O}$ modelo comunicacional do cyberspace ascendeu à berlinda de referência genérica, tornando-se o vórtice de desenvolvimento e reacomodação cultural e comercial dos media de massa. Outrora tensionalmente refechados em sua própria lógica, estes meios tomam agora, como espelho produtivo (ou, ao menos, levam exponencialmente em conta), em maior ou menor medida, a linguagem e os potenciais das tecnologias do virtual, bem como o seu modo de tratamento, apresentação e circulação de informações e imagens. Mais que isso, os media de massa, de par com todas as forças institucionais produtivas (corporativas, estatais e não-governamentais) do processo civilizatório atual, são, na verdade, estruturalmente dependentes das tecnologias e redes digitais.

[2] O cybespace absorve e equaliza todas as formas culturais disponíveis. Programas radiofônicos e televisivos e produtos da indústria bibliográfica, cinematográfica e musical sobrevêm agora, ostensivamente, pelo écran do objeto infotecnológico. Em sentido oposto, o acesso ao cybersapce via rede televisiva depende também de enquadramento ao código digital. 
[3] A produção do noticiário - em seja qual aspecto for, desde a mera captação da informação à sofisticação virtual da apresentação - se alimenta diuturnamente dos fluxos do cyberspace. O processo compreende a totalidade do ciclo social da comunicação: recepção, tratamento, armazenamento e retransmissão da informação.

[4] Não por outros motivos, as linguagens matriciais e operacionais da cultura mediática não se reduzem mais à conhecida tríade que predominou do final dos anos 40 a meados da década de 80 do século passado, a saber: [a] massificação cultural (ao nível mundial), [b] linguagem auto-referencial e (auto)promocional da publicidade e [c] entretenimento. As tendências de mercado, que materializam modos de apropriação social das invenções tecnológicas, catapultaram a interatividade (e a virtualidade), como linguagem, procedimento e desejo de época, ao patamar de valor social (quase) único [sob o álibi da quebra do monopólio do modelo de transmissão unilateral dos media de massa e (sob o álibi) da bi- ou multidirecionalidade em tempo real como "verdade da comunicação" (SFEZ, 1994, 275-277)].

[5] Essa recomposição de vetores se expressa nos (e, de certa forma, também justifica os) usos e abusos sociais do vocábulo "interatividade" pela agenda mediática de massa. A popularização paulatina do jargão responsável pela informatização da vida social - fama que não demonstra senão a desigual queda de braço tecnocultural em favor da cibercultura - tornou recorrentes procedimentos de remissão ao cyberspace, embora como crassos equívocos toleráveis de época. A emergência histórica do link, como solução utilitária para a estética digital da informação, acabou por engendrar, sob condições de predomínio do código da interatividade, essa sorte de link cultural difuso.

[6] Fatos, processos e relações tão ilustrativos não poderiam deixar de ter significado profundo. No conjunto, constituem termômetro confiável acerca do macrodeslocamento mediático que, já inteiramente cumprido em escala internacional, responde pelo advento social-histórico da cibercultura como categoria de época - acontecimento que propende, pois, em favor de seu conceito expandido. Categoria de época: a acepção nada tem a ver, portanto, com uma qualquer epistème da moda ou algo similar. Trata-se de conceito nuclear e articulatório que, abarcando 
a lógica do movimento do real, nomeia o contemporâneo e, portanto, pode ser mobilizada para melhor apreendê-la (seja no todo, seja em âmbitos particulares) e, naturalmente para - mais além do mero exercício terminológico -, tomá-la tensionalmente, como objeto de crítica teórica.

[7] Os pressupostos tecnológicos e discursivos da cibercultura radicam em tudo o que doravante vem ao mundo. A generalização do código digital como "sistema operacional" da vida social, econômica, política e cultural constitui base indispensável de sustentação da tese de que, há anos, a cibercultura vige, de algum modo, em algum grau de intensidade, inoculada na empiria processual predominante.

[8] Mais especificamente, com efeito, se a comunicação eletrônica é a forma predominante da cultura contemporânea (SFEZ, 1994) e se a fenomenologia da cibercultura, dentre suas ramificações nos subsistemas mencionados (economia, política, saúde, segurança, lazer etc.), tornou-se mais cativa da comunicação (TRIVINHO, 1999, Parte I, Cap. I, 2001, p. 69-62, 209-227), então a cibercultura equivale, em bloco, ao arranjamento atualmente predominante da civilização mediática. Sua acepção como categoria de época não deve ser apreendida de outro modo: estágio mais avançado da dromocracia mediática consolidada ao longo do século XX, doravante abrangendo os próprios media de massa, a cibercultura é a configuração societária (material, simbólica e imaginária) correspondente à fase digital do capitalismo tardio. Por esse motivo, ela se denomina, mais propriamente, dromocracia cibercultural, qualificada, de ponta a ponta, como transpolítica, eis que sua emergência, seu desenvolvimento, suas conseqüências e seu destino, jogando-se inteiramente no e pelo movimento do mercado, põem-se para além da capacidade de administração, gerenciamento e controle por parte das instituições políticas herdadas da modernidade (TRIVINHO, 2007, Parte II, Cap. 3).

\section{III - EXISTÊNCIA EM TEMPO REAL}

O contexto tecnocultural caracterizado acima perfaz o novo perímetro de injunções antropológicas no qual e a partir do qual se deve doravante apreender a significação social-histórica do fenômeno da existência em tempo real - ou, numa palavra, teleexistência. Embora esse fenômeno tenha se desenvolvido amplamente e 
se consolidado no contexto mediático de massa e nele assumido colorações específicas, correspondentes ao processo de transmissão unilateral, somente na cibercultura ele assumiu silhueta social e tecnocultural mais acabada - como processo condicionado e legitimado pela experiência coletiva e assim culturalmente sintetizado como um modo de existência -, à medida que o cyberspace transcendeu seu cativeiro militar e, depois, cumulativamente, acadêmico para se abrir a todas as iniciativas civis, alargando (embora aquém do esperado) a partilha social da experiência da comunicação bi- ou multidirecional simultânea.

\section{Conceito de existência em tempo real}

Para efeito da presente reflexão, o conceito de existência compreende o estatuto inexorável, irrecorrível e impenetrável do que é do que se põe no tempo enquanto uma presença, um que há, referente (abstrato ou concreto, palpável ou impalpável) que pode ser identificado como existente seja pela percepção, seja pelo verbo, seja ainda pela sensação; diz respeito ao estatuto de algo que deixou de ser o que não podia para tornar-se esse que é como presença que não pode deixar de ser. Diz-se, pois, desse que é - não importa por qual medida de tempo (se efêmero, se longevo) - que simplesmente existe e assim se faz somente na medida em que se põe (para o sujeito) como que é-sendo, como constância. Nessa condição, um existente somente pode ser confirmado num "encontro" (e num "acordo") simultâneo e múltiplo de três fatores no tempo, a saber, se houver confluência, no mesmo lapso, entre esse algo (o observado como um que é em processo), o observador (o que, como sujeito, é-sendo enquanto nota ou acompanha a existência do observado) e a percepção (o que é como ato que perdura tanto quanto a relação dos dois elementos).

Esse entendimento, conforme se depreende pela inclinação dos termos e sentidos, se inspira na noção de existência ou de existir tal como se apresenta na (e foi problematizada pela) filosofia existencialista e fenomenológica (cf. HEIDEGGER, 1958, 1978, 1986; SARTRE, 1999; MERLEAU-PONTY, 1971; MARCUSE, 1968), a partir da colocação à reflexão da conhecida indagação sobre o que significa algo, ou melhor, a existência de algo (seja ele o que for, para a percepção e para o 
pensamento) ou, antes, (a indagação sobre) por qual razão existe algo antes de haver nada (ou por que, antes de haver nada, há a "coisa”).4

O conceito de existência em tempo real pressupõe, fundamentalmente, a experiência da empiria processual do conceito de existência na acepção acima. Nomeia o processo comunicacional pelo qual algo se põe e se expõe, isto é, existe e se faz visível ou pode ser sentido na luz da velocidade da luz, com o estatuto apontado.

Por outro ângulo, existir em tempo real (quer dizer, o ato que concretiza o que a existência pressupõe ou denomina) é fazer-se ser no mesmo sentido (como processo, próprio do "ser" como verbo, não, obviamente, como algo dado (e pronto), como "substância", por assim dizer).

A unidade sociotécnica e cultural pela qual a existência ou o existir em tempo real se processa é o espectro [na acepção que lhe confere Guillaume (1989)], um existente mediático que, como signo (imagem, som e/ou texto) - ou, se se quiser, como simulacro (BAUDRILLARD, 1981, p. 9-68) -, remete a e simula ser um existente real ou que se passou no real [isto é, no mundo concreto dos objetosreferentes vivenciados e vivenciáveis (à falta de melhor expressão)] e nele já não vigora mais.

Em outras palavras, o fenômeno da existência em tempo real compreende um modo de exposição ou "transparenciação" do mundo, de seus entes (sujeitos e coisas), eventos e demais processos, literalmente a partir e através dessas unidades sígnicas geradas pelos media eletrônicos.

Não obstante, a questão contém importante sutileza. Longe de envolver simples apresentação e/ou representação de referentes do mundo, o tempo real forma-fluxo de cronologia condicionada por tecnologias eletrônicas capazes de rede evidencia, antes, presentação (cf. VIRILIO, 2002, 9-74, 137-165), isto é, forma-fluxo de exposição ou "transparenciação" de coisas, eventos e processos no mesmo instante em que eles o são ou se dão e exclusivamente sob a égide e sob a modalidade (de seu

4 As correntes teóricas de embasamento da reflexão são consignadas apenas como sinalização indispensável, em razão da exigüidade de espaço e da necessidade de liberá-lo exclusivamente para o esclarecimento extensivo e suficiente do mapa epistemológico nuclear da argumentação. 
equivalente modo) de informação e/ou imagem (estática ou dinâmica), um fazer e/ou fazer-se presente, um tornar e/ou tornar-se imediato (de maneira contínua, intermitente ou isolada) exclusivamente a partir e através da via mediática do espectro. A existência em tempo real se funda, necessariamente, não na mediatização de referentes no mundo, mas na própria conversão mediática do real numa profusão de "presentantes" sígnicos simulacionais, capazes, como tais, de vigorarem como realidade primeira, aparo fenomênico absoluto de referência para a relação com o outro e com o si-próprio, com o social, com a história e com a natureza.

O fenômeno da existência em tempo real, portanto, é algo mais que simplesmente "existir à distância" (conforme subentende, por força etimológica, a sua expressão apocopada). No caso do existir em tempo real, que, como ato processual, envolve, particularmente, o modo mediático pelo qual, por exemplo, um sujeito se põe na e através da rede, o processo remete à qualidade dinâmica de ser unicamente quando como espectro representativo-simulacional do referente (o próprio sujeito) assim "presentado" em tempo real - estatuto de ser que somente assim pode subsistir, ao mesmo tempo em que somente assim o sujeito consegue se constituir, isto é, como ser, em correspondência ao que, em regra, requer o tempo real como ditame de época. Essa experiência encerra, grosso modo, o significado ontológico e tecnocultural do que é "viver" no e como espectro, através e a partir dele.

\section{Experiência antropológica genérica}

Esse modo de existência configura experiência antropológica genérica, fato social total (cf. MAUSS, 1974, p. 39-184) - conforme assinalado na nota introdutória - da civilização mediática avançada. Seja pelos media de massa, seja pelos media interativos, seja ainda pela telefonia de base ou móvel, a teleexistência perfaz, de alguma maneira, em algum grau de intensidade, há bom par de anos, a experiência majoritária e diuturna de mundo para bilhões de pessoas. Ela é contexto-vórtice sociotécnico e cultural de articulação e modulação dos processos, eventos e tendências da vida social e da subjetividade na cibercultura. Dos fatos econômicos aos culturais, do trabalho ao tempo livre, estejam em jogo necessidades do Estado e/ou das organizações não-governamentais, da indústria e/ou do comércio, tudo passa ou tende a passar por esse "torvelinho de força" ou ser por ele perpassado. 
Na medida em que pressupõe a (experiência de imersão na) comunicação biou multidirecional simultânea (de massa ou interativa), a existência em tempo real constitui o supra-sumo das modalidades de experiência mediática possíveis e vigentes (vale dizer, de apropriação social dos media e redes), sobretudo no que isso diz respeito às tecnologias informáticas miniaturizadas e ao acesso sem fio. Se os media e redes se equiparam hoje ao "olho do furacão" tecnocultural contemporâneo, o fenômeno da teleexistência corresponde, por assim dizer, à quintessência desse processo. Sua experiência equivale àquela da dimensão mais sublime possibilitada pela condição glocal (adiante especificada).

\section{Glocalização como condição tecnocultural sine qua non da existência em tempo real 5}

A existência em tempo real tem como pressuposto tecnocultural sine qua non o processo de glocalização da vida humana, instituído no social-histórico pela apropriação social paulatina dos media eletrônicos ao longo do século XX.

O fenômeno glocal, de que tal processo deriva, sustém, estruturalmente, uma condição mediática de vida nem global, nem local, mas antes entretecida inextricavelmente por ambas as dimensões - então dissolvidas - num processo comunicacional único (não unívoco), de terceira via, socialmente fragmentário, descentrado e espargido, para além tanto da empiria abrangida pela categoria da globalização ou do globalismo (nos termos correntes, seja no âmbito das finanças e dos negócios, seja no da cultura e do entretenimento), quanto da empiria abrangida pelas categorias da localização, do localismo ou das culturas regionais.

A condição glocal configura, por pressuposto, a condição social-histórica inexorável, padrão e predominante, em que se encontram os indivíduos, corpos e espaços de vivência e interação (da rua ao domo, do trabalho ao tempo livre), bem como a economia, a política e a cultura na fase mediática avançada do capitalismo.

O enraizamento cotidiano da condição glocal é representado pelo contexto glocal, que responde pela disposição espacial (e cênica) daquela ao equivaler a uma ambiência mediática [em geral arranjada em lugares privativos (como o domo),

5 A matéria deste item, apenas mencionada em seus aspectos básicos, encontra-se desenvolvida em Trivinho (2007, Parte III, Cap. 1-2). 
embora não exclusivamente] de acesso/recepção/retransmissão de informações e imagens e, obviamente, de ocorrência do padrão majoritário de vivência da espiral social de signos.

\section{Pressupostos antropológicos e tecnoculturais da existência em tempo real / Teses}

A existência em tempo real, no que tange à sua significação social-histórica, suscita hipóteses e envolve evidências que a teoria social e, em particular, a teoria da comunicação podem assentar em prol da renovação e reescalonamento consistentes da categoria da crítica. Só as evidências, obviamente, podem ser arroladas na qualidade de teses. Ambas se referem às propriedades estruturais e, por assim dizer, “estáveis" do fenômeno, em sintonia com a profundidade de sua dimensão antropológica. À guisa de conclusão, arrolam-se abaixo os argumentos a respeito.

[1] A existência em tempo real representa a glocalização e a espectralização do hic et nunc da realidade ordinária herdada. À primeira visada, esse acontecimento parece totalmente sem importância e inofensivo. Envolve, entretanto, significado profundo, que aqui segue apenas sinalizado.

O hic et nunc, complexo universo do aqui e agora próprio da experiência vicária, presencial, material, do tempo-que-passa da existência cotidiana, identitário ao "mundo da vida" [para tomar de empréstimo uma expressão cara a HABERMAS (1987)], encontra-se reescalonado e inteiramente transformado na civilização mediática, em compatibilidade com um modus vivendi hegemonicamente marcado pela condição glocal: comparece como "tempo real" - tempo que subordina, com o seu agora tecnológico, milhões de contextos glocais -; e a sua experiência, como modo de existência na luz da velocidade da luz.

Esse reescalonamento e essa transformação significam, mais que uma imitação estratégica do hic et nunc da história legada, o agenciamento do mesmo ou, melhor, a sua cooptação - não raro em nome do entretenimento mediático e do hedonismo consumista -, sob o influxo de poderosos interesses políticos e econômicos. "Sugado" para dentro das estruturas glocais da vida social, ele não se encontra, com efeito, "colonizado", como que sob tutela, servidão ou vassalagem comunicacional; não segue aprisionado: sua glocalização apenas deu lugar a novo 
processo. A despeito de qualquer semelhança, enganosa em tudo, e de suas conexões imanentes e permanentes, a experiência do "hic et nunc" da existência em tempo real (se é que se pode usar impunemente a expressão latina nesse contexto) é culturalmente diversa da experiência do hic et nunc da existência em contexto presencial (não mediatizada), tanto em lógica, em estrutura, em dinâmica e em conseqüências.

A glocalização do hic et nunc é a representação sintética mais acabada do que, sob o processo de glocalização, ocorreu com todos os elementos e em diversos planos e dimensões da civilização mediática (trabalho, residência, corpo, subjetividade, comportamento, relacionamento, consumo, ação política, educação, e assim por diante).

[2] A existência em tempo real está na base da comutação/confusão contemporânea entre o imaginário e o real, o público e o privado, o interior e o exterior, o próximo e distante, o agora e o depois, como forma corolária contextual e direta da hibridação - no glocal - entre o hic et hunc da existência em contexto presencial e o hic et hunc da existência em tempo real.

[3] No que tange tanto ao indivíduo, grupo ou categoria social, quanto às organizações e instituições, a existência em tempo real sustém, em sua fenomenologia, por sua apropriação social, o condicionamento do valor, da validade e da atualidade do ser e do agir no mundo à exigência social reinante de inserção na visibilidade mediática.

[4] A existência em tempo real radica no centro de promoção cultural da dependência social absoluta e irreversível em relação aos media, ao contexto glocal e à visibilidade mediática, o que, em esteio à tese anterior, significa, em particular, que não se é um ser e não se desenvolve experiência cotidiana senão com o concurso de alguma máquina capaz de rede.

[5] Em relação à empiria da interatividade, a existência em tempo real rege e explica a dependência social do domínio (tanto mais privado e pleno quanto possível) das senhas infotécnicas de acesso ao cyberspace (especialmente, o objeto infotecnológico e o capital cognitivo conforme), o que, visto por epistème de maior alcance, compreende, ao nível do social-histórico, requalificação antropológica 
integral e extensiva (de massa) mediante domínio da dromoaptidão propriamente cibercultural (TRIVINHO, 2001, p. 219-227, 2007, Parte I, Cap. 2, Parte II, Cap. 2), direito social cuja distribuição, todavia, não é dada a todos.

[6] Pelas mesmas razões - em desdobramento direto da quarta tese - a existência em tempo real, seja no contexto glocal de massa, seja no ciberespacial ou telefônico, exige (e explica) a adesão coletiva dessimbólica ao princípio (então inquestionado) do acoplamento compulsório entre corpo, mente, máquina/tela e fluxos mediáticos. Axioma elementar e inflexível da comunicação como ideologia objetivada nas estruturas tecnológicas da vida social, ${ }^{6}$ tal adesão cauciona o mencionado vínculo inextricável, só aparentemente omeostático e harmônico, hoje instituído como modus vivendi tecnocultural conservador (de que, aliás, a interatividade é hoje a herdeira mais pródiga e também o seu emblema mais ostensivo).

[7] A existência em tempo real - conforme adiantado no tópico III, item 1 vigora sobre a base do (e se alimenta, diuturna e fundamentalmente, do) amplo referendo ao processo social (de propriedades civilizatórias) que equaciona a natureza espectral da visibilidade mediática à condição de realidade prioritária, como se a surpreendente multiplicidade de acontecimentos e pulsações da vida humana e da natureza se restringisse exclusivamente ao que transita pelas ondas magnéticas, reducionismo cultural objetivo que nem mesmo o cyberspace conseguiu dissolver ou redimir.

[8] Em conseqüência, o fenômeno da existência em tempo real pressupõe (e promove socialmente) a condenação sumária do "resto" à periferia mediática (permanente ou intermitente), larga zona simbólica que, como gulag invisível, os valores correntes arquitetam com qualificativos degradantes ou, ao menos, pejorativos. O ostracismo simbólico típico da civilização mediática, que expõe per se a arrogância institucional e maniqueísta dos media como eixo cultural de referência, repete, em silêncio, a sentença que, como cantilena, lhe é identitária: o que comparece na visibilidade mediática tem importância; o que não o faz não dispõe, por assim dizer, de glamour; o que flui pelo espectro existe (não importa com

\footnotetext{
6 A passagem incorpora a noção de ideologia proposta por Adorno e Horkheimer (1973, p. 184-205), Marcuse (1967) e Habermas (1980, 2001).
} 
qual valor, que, não raro, pode ser negativo); o que não o faz tem "peso" social e cultural zero, como se não tivesse o menor direito à existência.

[9] A existência em tempo real, na medida em que deriva do incremento progressivo, como habitus de espécie (isto é, não como comportamento de época), do investimento social no universo das redes eletrônicas, constitui, portanto, um dos fios condutores do (e que explicitam o) decréscimo histórico, ao nível do padrão subjetivo de massa, do interesse social pelo território geográfico e, em particular, pelo espaço urbano (VIRILIO, 1984, 1995, 2002; TRIVINHO, 2007, Parte I, Cap. 1, Parte III, Cap. 3), no qual a humanidade havia realizado exclusivamente a sua socialização antes da massificação do contexto glocal. Epifenômeno da denegação obliteradora da materialidade da existência (então convertida em extensão hiperbólica e inútil) em favor do espectro como vetor de referenciação, trata-se, in solidum, de um deslocamento desvalorizante que, "lançando" o território geográfico à zona de exclusão mediática, o subtrai paulatinamente do diapasão perceptivo corrente.

[10] Na esteira avançada do processo condenatório de desaparecimento da materialidade do mundo (vis-à-vis, de sua reinvenção no contexto glocal) (TRIVINHO, 1999, 2007, Parte III, Cap. 3), a experiência da existência em tempo real, como habitus - enfatize-se apenas, uma vez já dada a sinalização -, se nutre de (e avaliza e fomenta a) inteira anuência (consciente ou inconsciente) em relação à sociabilidade espectral e, nesse cenário, ao tratamento da alteridade como puro signo.

[11] Como fundamento dessas injunções, a existência em tempo real condiciona o seu modus operandi à naturalização de todas as suas condições de base e de fundo, como se nada se passasse de problemático, como se o mundo fosse assim e devesse sempre sê-lo, sem razões para a diferença. A naturalização dessas condições elementares denuncia o seu próprio substrato: a rendição tácita (voluntária ou involuntária) ao modelo e à dinâmica tecnológicos da civilização em curso, a partir da assunção, como verdade, dos padrões de visão e de sensibilidade necessários à legitimação dessa civilização.

[12] Por fim, a tese mais importante da presente reflexão: todos os pressupostos acima, com destaque para a função desempenhada pela referida 
naturalização, constam, em combustão, mobilizados na e para a reprodução socialhistórica e cultural da civilização mediática avançada. Conforme pontuado na nota introdutória, a existência em tempo real joga papel de extrema relevância na dinâmica interna da fase atual do modo de produção capitalista e em sua reescritura cibercultural completa. Reverberação mediática de interesses estruturais e convenientes - de megacorporações do ramo, Estados e consumidores (ouvintes/telespectadores/usuários) -, articulado e sustentado, pois, pelo valor de troca típico da atualidade (impreciso, flutuante e incerto), é com base na e através da experiência desse fenômeno (numa palavra, nas e pelas práticas glocais, em especial no âmbito do cyberspace) que muito se fortalecem os alicerces multilaterias necessários à pretensa imortalização do processo civilizatório vigente.

Em síntese, dos aspectos mais empíricos e prosaicos aos mais abstratos e complexos, o fenômeno da existência em tempo real revela, de maneira definida, na era da cibercultura, uma significação social-histórica sui generis que perfaz o ciclo que se estende da subordinação subjetiva e social a elementos tecnológicos de base até a produção de subjetividade e habitus previsíveis, em garantia compatível à posteridade da civilização glocal.

\section{Referências}

ADORNO, Theodor Wisenground; HORKHEIMER, Max. (Org.). Temas básicos de Sociologia. São Paulo: Cultrix; EDUSP, 1973.

BAUDRILLARD, Jean. Simulacres et simulations. Paris: Galilée, 1981. . A transparência do mal: ensaios sobre os fenômenos extremos. São Paulo: Papirus, 1990.

. O crime perfeito. Lisboa: Relógio D’Água, 1996. (Col. Mediações).

GUILLAUME, Marc. La contagion des passions: essai sur l'exotisme intérieur. Paris: Plon, 1989.

HABERMAS, Jürgen. A crise de legitimação no capitalismo tardio. Rio de Janeiro: Tempo Brasileiro, 1980.

. Teoría de la acción comunicativa. Madrid: Taurus, t.1 e 2, 1987. . Técnica e ciência como ideologia. Lisboa: Ed. 70, 2001. 
HEIDEGGER, Martin. Essais et conferénces. Paris: Gallimard, 1958. . Introdução à metafísica. Rio de Janeiro: Tempo Brasileiro, 1978. . Être et temps. Paris: Gallimard, 1986.

MARCUSE, Herbert. Ideologia da sociedade industrial. Rio de Janeiro: Zahar, 1967.

Materialismo histórico e existência. Rio de Janeiro: Tempo Brasileiro, 1968.

MAUSS, Marcel. Sociologia e antropologia. São Paulo: EPU; EDUSP, v. II, 1974.

SARTRE, Jean-Paul. O ser e o nada: ensaio de ontologia fenomenológica. 7. ed. Petrópolis: Vozes, 1999.

SFEZ, Lucien. Crítica da comunicação. São Paulo: Loyola, 1994.

TRIVINHO, Eugênio. Cyberspace: crítica da nova comunicação. São Paulo: Biblioteca da ECA/USP, 1999. 466 p.

. O mal-estar da teoria: a condição da crítica na sociedade tecnológica atual. Rio de Janeiro: Quartet, 2001.

. A dromocracia cibercultural: lógica da vida humana na civilização mediática avançada. São Paulo: Paulus, 2007. (No prelo.)

VIRILIO, Paul. L'espace critique. Paris: Christian Bourgois, 1984.

La vitesse de libération. Paris: Galilée, 1995.

. L’inertie polaire: essai. Paris: Christian Bourgois, 2002. 